\title{
Intra-operative hydroxyethyl starch is not associated with post-craniotomy hemorrhage
}

\author{
James A Feix ${ }^{1}$, C Andrew Peery ${ }^{1}$, Tong J Gan ${ }^{1,4}$, David S Warner ${ }^{1,2}$, Michael L James ${ }^{1,3}$, Ali Zomorodi² \\ and David L McDonagh ${ }^{1,5^{*}}$
}

\begin{abstract}
Background: Intraoperative intravascular volume expansion with hydroxyethyl starch-based colloids is thought to be associated with an increased risk of post-craniotomy hemorrhage. Evidence for this association is limited. Associations between resuscitation with hydroxyethyl starch and risk of repeat craniotomy for hematoma evacuation were examined.

Methods: Using a retrospective cohort of neurosurgical patients at Duke University Medical Center between March 2005 and March 2012, patient characteristics were compared between those who developed post-craniotomy hemorrhage and those who did not.

Results: A total of 4,109 craniotomy procedures were analyzed with 61 patients having repeat craniotomy for postoperative hemorrhage (1.5\%). The rate of reoperation in the group receiving $6 \%$ High Molecular Weight Hydroxyethyl Starch $\left(\right.$ Hextend $\left.{ }^{\circledR}\right)$ was 2.6 vs. $1.3 \%$ for patients that did not receive hetastarch $(P=0.13)$. The reoperation rate for those receiving $6 \%$ hydroxyethyl Starch 130/0.4 (Voluven ${ }^{\circledR}$ ) was 1.4 vs. $1.6 \%$ in patients not receiving Voluven $(P=0.85)$.

Conclusions: In this retrospective cohort, intra-operative hydroxyethyl starch was not associated with an increased risk of post-craniotomy hemorrhage.
\end{abstract}

Keywords: Colloid, Hydroxyethyl starch, Hemorrhage, Neuroanesthesia, Craniotomy, Neurosurgery

\section{Background}

Hydroxyethyl starch (HES) based colloids have gained popularity in clinical anesthesia practice due to their effective intravascular volume expansion (Kozek-Langenecker 2005). Recently, there have been studies warning providers to limit the volume infused because of concerns for platelet dysfunction and increased bleeding (Kozek-Langenecker 2005; Westphal et al. 2009; Myburgh and Mythen 2013; Hartog et al. 2011), based on in vitro coagulation abnormalities (Avorn et al. 2003; Wilkes et al. 2001; Strauss 1981). For example, in a porcine model of liver trauma HES has been shown

\footnotetext{
*Correspondence: david.mcdonagh@utsouthwestern.edu

${ }^{5}$ Departments of Anesthesiology, Neurology, \& Neurosurgery, University of Texas Southwestern, 5323 Harry Hines Blvd., Dallas, TX 75390-9068, USA Full list of author information is available at the end of the article
}

to provoke uncontrolled hemorrhage (Zaar et al. 2009). Similarly, in a small prospective randomized trial of 40 patients undergoing major surgery the impact of HES on coagulation was apparent, as HES reduced clot strength and increased perioperative hemorrhage by more than 50\% (Rasmussen et al. 2014). Even when used at less than the recommended maximum dose, HES use has been associated with increased postoperative bleeding and transfusion in patients undergoing heart surgery requiring cardiac bypass (Avorn et al. 2003; Wilkes et al. 2001). There have also have been small studies associating the use of HES with intracranial bleeding and coagulopathy in the setting of subarachnoid hemorrhage (Damon et al. 1987; Knutson et al. 2000). The mechanisms causing this acquired coagulopathy include qualitative platelet dysfunction, decreases in Factor VIII/von Willebrand's factor complexes (sometimes referred to as "Acquired von

\section{贷 Springer}

(c) 2015 Feix et al. This article is distributed under the terms of the Creative Commons Attribution 4.0 International License (http:// creativecommons.org/licenses/by/4.0/), which permits unrestricted use, distribution, and reproduction in any medium, provided you give appropriate credit to the original author(s) and the source, provide a link to the Creative Commons license, and indicate if changes were made. 


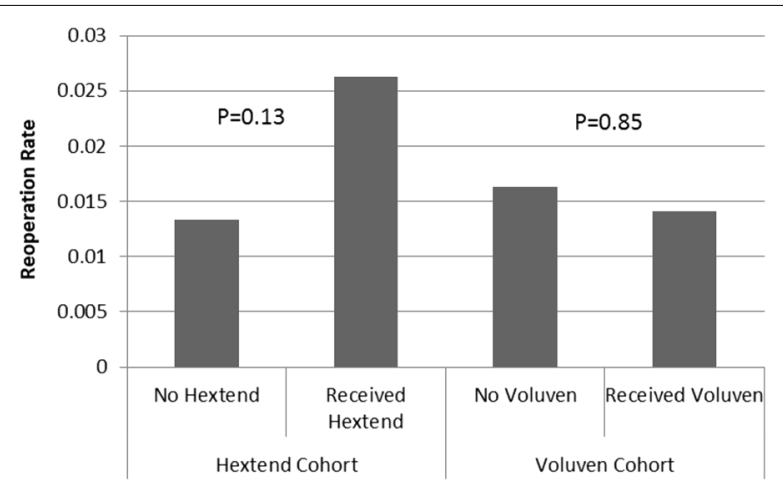

Figure 1 Comparison of reoperation rates (for postcraniotomy hemorrhage) for patients who did or did not receive HES products.

Willebrand's disease-Type 1"), and qualitative disruption of fibrin clots (Trumble et al. 1995; Jonville-Bera et al. 2001).

The cranium is a closed compartment where small volumes of blood can cause clinical, even life-threatening, symptoms. Previous studies show that $1-2 \%$ of post-craniotomy patients have symptomatic hemorrhage requiring intervention (Treib et al. 1999; Field et al. 2001). We aimed to determine whether intraoperative HES administration, compared with no HES, was associated with post-craniotomy hemorrhage requiring reoperation in a large retrospective cohort.

\section{Results}

Out of a total of 4,109 craniotomy procedures, 61 patients underwent repeat craniotomy for post-operative hemorrhage. The overall reoperation rate for postoperative intracranial hemorrhage was $1.5 \%$. The mean \pm SD estimated blood loss was $331 \pm 415 \mathrm{~mL}$ (Range 5-7,200 mL) and the average volume of crystalloid administered was 2,704 $\pm 1,863 \mathrm{~mL}$ (Range 75-20,200 mL). HES was used in 334 operations $\left(8.1 \%\right.$ of cases), including Hextend ${ }^{\circledR}$ use in 190 cases $(5.0 \%)$ and Voluven ${ }^{\circledR}$ in 144 cases $(2.8 \%)$ (Figure 1). The average volume of Hextend ${ }^{\circledR}$ administered was $635 \pm 286 \mathrm{~mL}$ (Range 100-1,600 mL) and the average volume of Voluven ${ }^{\circledR}$ was $725 \pm 350 \mathrm{~mL}$ (Range 250-2,000 mL).

Between March 2005 and March 2010, when Hextend ${ }^{\circledR}$ was in use, a total of 2,883 craniotomies were performed. Of these procedures, $41(1.4 \%)$ patients had a repeat craniotomy for post-operative hemorrhage. The postoperative hemorrhage group was more likely to be male, to have a tumor or trauma as the reason for craniotomy, and to have received a greater volume of crystalloid and packed red blood cells compared with those who did not have a post-operative hemorrhage (Table 1). During this time, there was no significant difference in the proportion of patients who received Hextend ${ }^{\circledR}$ among those who had a post-operative hemorrhage and those who did not (Table 1).

Between March 2010 and March 2012, when Voluven ${ }^{\circledR}$ was in use, a total of 1,287 craniotomies were performed. Of these procedures 20 (1.6\%) patients had a repeat craniotomy for post-operative hemorrhage. The post-operative hemorrhage group was more likely to be older, to have a greater ASA Grade, and to have received packed red blood cells, fresh frozen plasma, and platelets compared to those who did not have a post-operative hemorrhage. During this time, there was no difference in the proportion of patients who received Voluven ${ }^{\circledR}$ among those who had a post-operative hemorrhage requiring repeat craniotomy and those who did not (Table 2). Reoperation occurred most commonly on post-operative day 1 (Figure 2).

\section{Discussion}

Intraoperative HES use was not associated with reoperation for intracranial bleeding after craniotomy in our cohort. Similarly, Jian and colleagues found that HES was not a risk factor for post-craniotomy intracranial hematoma requiring surgery (Jian et al. 2014). The rate of reoperation for post-craniotomy intracranial hemorrhage in our cohort is similar to previously published rates (Field et al. 2001). Reoperation occurred most commonly on post-operative day 1 , consistent with previous studies of post-operative hematoma evacuations (Jian et al. 2014; Kelly et al. 2011).

Our study has limitations. This is a secondary analysis performed using observational data collected at a single institution. We did not perform multivariate analyses to adjust for confounding variables. We also did not quantitatively examine dose-response between HES and blood loss because of the limited accuracy of retrospective HES dose and estimated blood loss data. We focused on repeat craniotomy for hemorrhage because it was an unambiguous endpoint. The study is underpowered to detect an increase in repeat craniotomies for post-operative hematoma in those exposed to HES, although our data indicate that the effect size is quite small. Our data may be helpful for any investigators planning prospective studies of HES in craniotomy patients. Based on our data, a future prospective study investigating the use of HES in craniotomy would need a sample size of 5,790 patients to have $80 \%$ power to detect an increase in repeat craniotomies for post-operative hematoma from 1.4\% (HES group) to $2.1 \%$ (No-HES group) using a two-group Chi square test with a 0.05 two-sided significance level. This effect size is an odds ratio of 1.511 . 
Table 1 Demographic and clinical characteristics of the March 2005-March 2010 Cohort

\begin{tabular}{|c|c|c|c|}
\hline & $\begin{array}{l}\mathrm{N}=2,801 \\
\text { No repeat craniotomy for } \\
\text { post-operative hemorrhage }\end{array}$ & $\begin{array}{l}\mathrm{N}=41 \\
\text { Repeat craniotomy for } \\
\text { post-operative hemorrhage }\end{array}$ & $p$ value \\
\hline Mean age, years (SD) & $51.0(16.0)$ & $54.6(15.5)$ & 0.7 \\
\hline Male, n (\%) & $1,322(47.4)$ & $25(62.5)$ & 0.06 \\
\hline ASA grades $1-2, n(\%)$ & $1,236(46.9)$ & $20(50.0)$ & 0.82 \\
\hline ASA grades 3-5, n (\%) & $1,152(53.1)$ & $20(50.0)$ & 0.82 \\
\hline E Cases, n (\%) & $328(12.1)$ & $2(5.0)$ & 0.18 \\
\hline Tumor, n (\%) & $1,393(49.7)$ & $32(80.0)$ & $<0.0001$ \\
\hline Vascular, n (\%) & $305(10.9)$ & $6(15.0)$ & 0.23 \\
\hline Trauma/other, n (\%) & $1,104(39.5)$ & $2(5.0)$ & $<0.0001$ \\
\hline Baseline coagulopathy, n (\%) & $58(2.1)$ & $1(2.5)$ & 0.85 \\
\hline Mean EBL, mL (SD) & $279.1(391.9)$ & $540.2(1,176.2)$ & 0.16 \\
\hline Mean operation length, min (SD) & $229.2(120.6)$ & $226.3(159.5)$ & 0.15 \\
\hline Mean crystalloid volume, mL (SD) & 2,694.9 (1909.5) & $3,620.7(2,351.1)$ & $<0.0001$ \\
\hline Received plasmanate* ${ }^{*} \mathrm{n}(\%)$ & $420(14.7)$ & $8(19.5)$ & 0.38 \\
\hline Mean plasmanate* volume, $\mathrm{mL}(\mathrm{SD})$ & $529.7(352.9)$ & 750 (353.6) & 0.21 \\
\hline Received hextend, n (\%) & $185(6.6)$ & $5(12.5)$ & 0.15 \\
\hline Mean hextend volume, mL (SD) & $635.4(286.9)$ & $650(335.4)$ & 0.89 \\
\hline Received PRBCs, n (\%) & $194(6.9)$ & $3(7.5)$ & 0.89 \\
\hline Mean PRBCs volume, mL (SD) & $877.5(901.5)$ & $2,450(1,603.9)$ & 0.003 \\
\hline Received FFP, n (\%) & $82(2.9)$ & $3(7.5)$ & 0.09 \\
\hline Mean FFP volume, mL (SD) & $660.2(603.0)$ & $1,227(1,050.7)$ & 0.12 \\
\hline Received platelets, n (\%) & $91(3.2)$ & $1(2.5)$ & 0.77 \\
\hline Mean platelets volume, mL (SD) & $353.0(208.6)$ & $563(-)$ & - \\
\hline
\end{tabular}

* Plasmanate is a purified plasma derivative consisting predominantly of human albumin.

\section{Conclusions}

In conclusion, these data did not demonstrate an association between HES use during craniotomy and post-craniotomy hemorrhage. Whether low-volume intraoperative HES bolus dosing has adequate safety requires further study.

\section{Methods}

After IRB approval was obtained, all craniotomy procedures at Duke University Medical Center between March 2005 and March 2012 were retrospectively reviewed using Duke Enterprise Data Unified Content Explorer (DEDUCE) and the electronic anesthesia records (Innovian, Drager, Telford, PA, USA). Patients undergoing reoperation within 30 days for intracranial hemorrhage were identified. If the operative note from the second operation indicated that the repeat craniotomy was to treat intracranial hemorrhage, such patients were placed in "Repeat Craniotomy for Postoperative Hemorrhage" group. All other craniotomy patients were placed in the "No Repeat Craniotomy for Postoperative Hemorrhage" group. Demographic information was obtained as well as relevant risk factors for post-operative bleeding including preoperative coagulation parameters, estimated blood loss, and operative site. HES use and other intraoperative fluids were identified from electronic anesthesia records associated with these cases. Of note, the attending neurosurgeons performing the majority of craniotomies as well as the intravenous fluids (normal saline and Ringer's lactate) administered were consistent over the period of the study.

In March 2010, there was an institutional switch from Hextend ${ }^{\circledR}$ (HES 6\%/200/0.5) to Voluven ${ }^{\circledR}$ (HES $6 \% / 130 / 0.4)$. Our data set includes both HES products and analyzes data for each product separately.

\section{Statistical analysis}

Means and standard deviations were reported for continuous variables. Medians were reported for skewed distributions of continuous variables. Proportions were reported for categorical data. Characteristics were compared using a 2 sample $t$ test or Pearson's Chi square 
Table 2 Demographics and clinical characteristics of the March 2010 and March 2012 cohort

\begin{tabular}{|c|c|c|c|}
\hline & $\begin{array}{l}\mathrm{N}=1,247 \\
\text { No repeat craniotomy for } \\
\text { post-operative hemorrhage }\end{array}$ & $\begin{array}{l}\mathrm{N}=20 \\
\text { Repeat craniotomy for } \\
\text { post-operative hemorrhage }\end{array}$ & $p$ value \\
\hline Mean age, years (SD) & $51.6(16.3)$ & $61.8(14.8)$ & 0.007 \\
\hline Male, $n(\%)$ & $632(50.7)$ & $9(45.0)$ & 0.61 \\
\hline ASA grades $1-2, n(\%)$ & $488(39.1)$ & $2(10.0)$ & 0.008 \\
\hline ASA grades $3-5, n(\%)$ & $734(58.9)$ & $18(90.0)$ & 0.008 \\
\hline E Cases, n (\%) & $112(9.0)$ & $1(5.0)$ & 0.53 \\
\hline Tumor, n (\%) & $784(62.9)$ & $13(65.0)$ & 0.72 \\
\hline Vascular, n (\%) & $288(23.1)$ & $3(15.0)$ & 0.39 \\
\hline Trauma/other, n (\%) & $175(14.0)$ & $4(20.0)$ & 0.45 \\
\hline Baseline coagulopathy, n (\%) & $15(1.2)$ & $0(0)$ & 0.62 \\
\hline Mean EBL, mL (SD) & $297.5(345.2)$ & $236.1(157.7)$ & 0.11 \\
\hline Mean operation length, min (SD) & $212.1(109.9)$ & $197.7(138.5)$ & 0.65 \\
\hline Mean crystalloid volume, mL (SD) & $2,390.5(1,482.8)$ & $2,683.8(1,494.2)$ & 0.39 \\
\hline Received plasmanate*, n (\%) & $202(16.2)$ & $2(10.0)$ & 0.45 \\
\hline Mean plasmanate* volume, $\mathrm{mL}(\mathrm{SD})$ & $510.4(288.8)$ & $625(176.8)$ & 0.53 \\
\hline Received voluven, n (\%) & $142(11.4)$ & $2(10.0)$ & 0.85 \\
\hline Mean voluven volume, mL (SD) & $664.4(287.7)$ & 750 (353.6) & 0.67 \\
\hline Received PRBCs, n (\%) & $72(5.8)$ & $3(15.0)$ & 0.08 \\
\hline Mean PRBCs volume, mL (SD) & $832.2(893.4)$ & $350(0)$ & $<0.001$ \\
\hline Received FFP, n (\%) & $39(3.1)$ & $3(15.0)$ & 0.003 \\
\hline Mean FFP volume, mL (SD) & $583.3(605.1)$ & $539.67(68.7)$ & 0.67 \\
\hline Received platelets, n (\%) & $38(3.1)$ & $2(10.0)$ & 0.08 \\
\hline Mean platelets volume, mL (SD) & $360.1(226.7)$ & $249(69.3)$ & 0.5 \\
\hline
\end{tabular}

* Plasmanate is a purified plasma derivative consisting predominantly of human albumin.

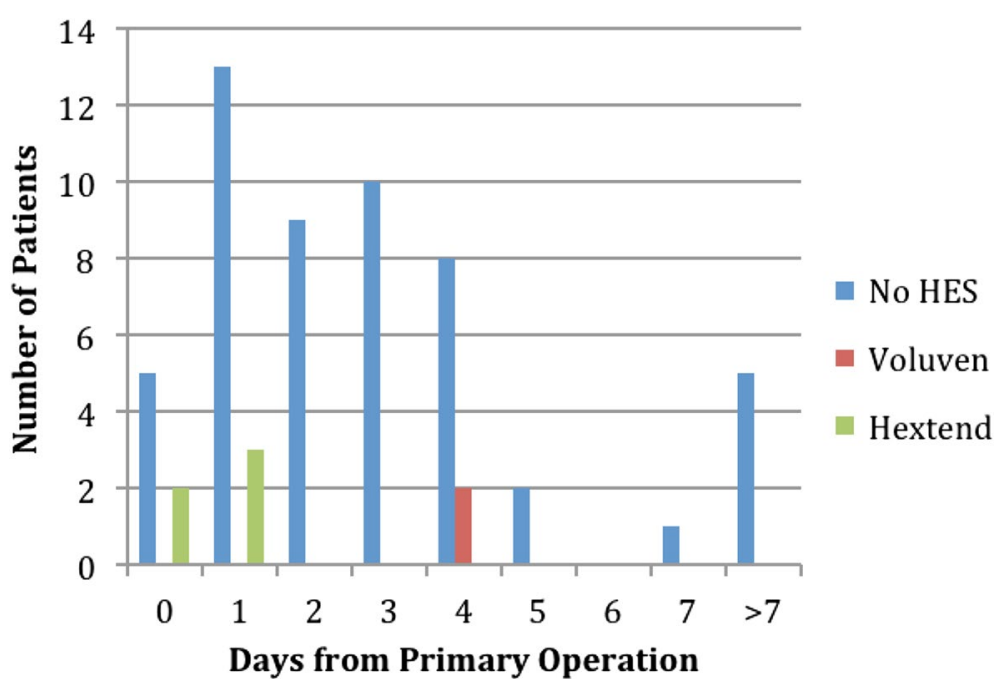

Figure 2 Timeline indicating when (post-operative day) patients returned for repeat craniotomy for hemorrhage. 
test. All tests of significance were two-tailed and $\mathrm{p}$ values $<0.05$ were considered significant. The analysis was performed using SAS 9.2 (SAS, Cary, North Carolina).

\section{Authors' contributions}

JAF-data gathering and interpretation, manuscript writing. CAP—data interpretation and manuscript writing. TJG, DSW-experimental design, data interpretation, manuscript editing, and review. MLJ, AZ- data review, manuscript editing and review. DLM_experimental design, data gathering and interpretation, manuscript writing. All authors read and approved the final manuscript.

\section{Author details}

${ }^{1}$ Department of Anesthesiology, Duke University Medical Center, Durham, NC, USA. ${ }^{2}$ Department of Neurosurgery, Duke University Medical Center, Durham, NC, USA. ${ }^{3}$ Department of Neurology, Duke University Medical Center, Durham, NC, USA. ${ }^{4}$ Department of Anesthesiology, Stony Brook University, Stony Brook, NY, USA. ${ }^{5}$ Departments of Anesthesiology, Neurology, \& Neurosurgery, University of Texas Southwestern, 5323 Harry Hines Blvd., Dallas, TX 75390-9068, USA.

\section{Acknowledgements}

Statistical assistance was provided by Barbara Phillips-Bute, Ph.D., who has left Duke University and moved on to a new career as an attorney. We greatly appreciate her efforts on behalf of this work.

\section{Compliance with ethical guidelines}

Competing interests

Dr. McDonagh is a consultant for Cephalogics Corp., LLC.

\section{Funding}

Duke University Department of Anesthesiology.

\section{Ethical approval}

IRB approval was obtained prior to this study.

Received: 10 March 2015 Accepted: 29 June 2015

Published online: 16 July 2015

\section{References}

Avorn J, Patel M, Levin R, Winkelmayer WC (2003) Hetastarch and bleeding complications after coronary artery surgery. Chest 124:1437-1442

Damon L, Adams M, Stricker RB, Ries C (1987) Intracranial bleeding during treatment with hydroxyethyl starch. N Engl J Med 317:964-965
Field M, Witham TF, Flickinger JC, Kondziolka D, Lunsford LD (2001) Comprehensive assessment of hemorrhage risks and outcomes after stereotactic brain biopsy. J Neurosurg 94:545-551

Hartog CS, Reuter D, Loesche W, Hofmann M, Reinhart K (2011) Influence of hydroxyethyl starch (HES) 130/0.4 on hemostasis as measured by viscoelastic device analysis: a systematic review. Intensive Care Med 37:1725-1737

Jian M, Li X, Wang A, Zhang L, Han R, Gelb AW (2014) Flurbiprofen and hypertension but not hydroxyethyl starch are associated with post-craniotomy intracranial haematoma requiring surgery. $\mathrm{Br} J$ Anaesth 113(5):832-839. doi:10.1093/bja/aeu185

Jonville-Bera AP, Autret-Leca E, Gruel Y (2001) Acquired type I von Willebrand's disease associated with highly substituted hydroxyethyl starch. N Engl J Med 345:622-623

Kelly KP, Janssens MC, Ross J, Horn EH (2011) Controversy of non-steroidal anti-inflammatory drugs and intracranial surgery: et ne nos inducas in tentationem? Br J Anaesth 107:302-305

Knutson JE, Deering JA, Hall FW, Nuttall GA, Schroeder DR, White RD et al (2000) Does intraoperative hetastarch administration increase blood loss and transfusion requirements after cardiac surgery? Anesth Analg 90(4):801-807

Kozek-Langenecker SA (2005) Effects of hydroxyethyl starch solutions on hemostasis. Anesthesiology 103:654-660

Myburgh JA, Mythen MG (2013) Resuscitation fluids. N Engl J Med 369:1243-1251

Rasmussen KC, Johansson PI, Højskov M, Kridina I, Kistorp T, Thind P et al (2014) Hydroxyethyl starch reduces coagulation competence and increases blood loss during major surgery: results from a randomized controlled trial. Ann Surg 259(2):249-254. doi:10.1097/SLA.0000000000000267

Strauss RG (1981) Review of the effects of hydroxyethyl starch on the blood coagulation system. Transfusion 21:299-302

Treib J, Baron JF, Grauer MT, Strauss RG (1999) An international view of hydroxyethyl starches. Intensive Care Med 25:258-268

Trumble ER, Muizelaar JP, Myseros JS, Choi SC, Warren BB (1995) Coagulopathy with the use of hetastarch in the treatment of vasospasm. J Neurosurg 82:44-47

Westphal M, James MF, Kozek-Langenecker S, Stocker R, Guidet B, Van Aken $H$ (2009) Hydroxyethyl starches: different products-different effects. Anesthesiology 111:187-202

Wilkes MM, Navickis RJ, Sibbald WJ (2001) Albumin versus hydroxyethyl starch in cardiopulmonary bypass surgery: a meta-analysis of postoperative bleeding. Annal Thorac Surg 72:527-533 (discussion 534)

Zaar M, Lauritzen B, Secher NH, Krantz T, Nielsen HB, Madsen PL et al (2009) Initial administration of hydroxyethyl starch vs lactated Ringer after liver trauma in the pig. Br J Anaesth 102(2):221-226. doi:10.1093/bja/aen350

\section{Submit your manuscript to a SpringerOpen ${ }^{\circ}$ journal and benefit from:}

- Convenient online submission

- Rigorous peer review

- Immediate publication on acceptance

- Open access: articles freely available online

- High visibility within the field

- Retaining the copyright to your article

Submit your next manuscript at $>$ springeropen.com 